\title{
FOPID Controller Design and Implementation for High Gain Quadratic Boost Switched Capacitor Converter
}

\author{
Sivaraj Desingu ${ }^{1 *}$, Arounassalame Mouttou $^{1}$ \\ 1 Department of Electrical and Electronics Engineering, Pondicherry Engineering College, East Coast Road, 605014 Pillaichavadi, \\ Puducherry, India \\ * Corresponding author, e-mail: sivaraj2d@gmail.com
}

Received: 20 February 2020, Accepted: 17 May 2020, Published online: 08 October 2020

\begin{abstract}
In Solar panel and UPS, high gain DC-DC converters are commonly used. In grid connected inverter specifications, the batteries and solar panel voltage level are low. The use of multiple series related DC batteries and PV panels directly connected to the inverter, it simplifies the process, but the expense is high, and efficiency is low. A high-gain Quadratic Boost Switched Capacitor Converter is proposed in this paper. The high step up voltage gain is achieved by adding the voltage multiplier topology in the conventional quadratic boost converter with the correct duty ratio. The fractional order controller is implemented, and it's tuned by genetic algorithm optimization method for improving the performance of the proposed converter. Its characteristics are low energy processing, robustness and balanced voltage of cells. The performed that include the proposal and existing solutions, the theoretical results are verified from MATLAB/SIMULINK toolbox.
\end{abstract}

\section{Keywords}

Quadratic Boost Switched Capacitor Converter (QBSCC), fractional order PID controller, high gain, transient analysis, steady state analysis, genetic algorithm

\section{Introduction}

In recent years, PV systems, fuel cell, wind energy and more energy applications are developed to address the global energy shortage issues [1, 2]. Fuel cell generating system provides electric power normally in the range of $6 \mathrm{~V}$ to $48 \mathrm{~V}$, which is not appropriate for high voltage applications. Some high gain DC-DC converters are used to boost up the voltage in the range of $200 / 400 \mathrm{~V} \mathrm{DC}$, further it is converter to AC voltage by DC-AC inverter for grid connected applications shown in Fig. 1.

The isolated DC-DC converter provides high gain DC voltage by adjusting the turn's ratio of transformer and regenerating technique are employed by clamping the voltage [3-5]. Non-isolated DC-DC converters are attracted

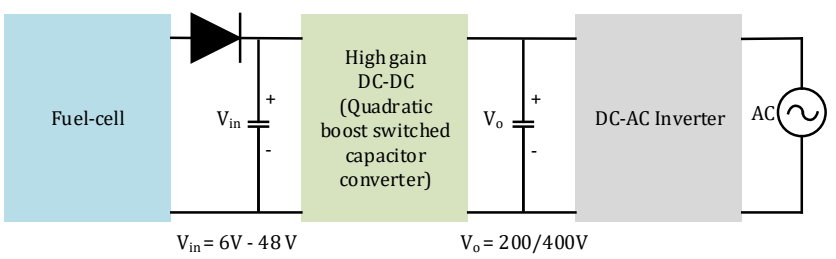

Fig. 1 Fuel cell power generation system by low and medium power applications because of its advantage like simplicity, low cost and improved efficiency than isolated converter. A $15 \mathrm{~V}$ input, $200 \mathrm{~V}$ output, $100 \mathrm{~W}$ DC-DC boost converter for micro grid application is presented in [6], however high gain is achieved through the coupled inductor. Due to the leakage inductance of transformer voltage spike are produced across the switches, mostly in high gain converter two or more switches are used, it leads to switching stress. To improve the reliability, safe, economics of the commercial fuel cell EV hybrid systems are developed by Energy Storage Devices (ESDs) optimization [7, 8], battery charger [9], local renewable energy for electric vehicle and charging management are explained $[9,10]$.

Power converter plays an important role to boost up the voltage from $100 \mathrm{~V}$ to $400 \mathrm{~V}$ through a DC bus link, super capacitor system with a low input current ripple [11, 12]. Recently high gain quadratic boost converter is coupled with Cuk converter to overcome the need of high voltage gain and reduced input current ripple. Quadratic DC-DC Boost-Cuk HQBC converter type I and type II 
are examined in detail [13]. From the study, the controller implementation of the modified high gain converter is very minimum and very few control techniques are adopted only for the quadratic boost converter. Controller is very essential to improve the dynamic and static performance for the static load and dynamic load. Non minimum phase behavior of the quadratic boost converter modeling, analysis and some control technique like average current-mode controller, two loop integer order controllers, sliding mode controller have been widely discussed in the literature [14-20].

This paper concentrates on improving the output voltage gain by designing of hybrid DC-DC converter (i.e., combination of quadratic boost converter and voltage multiplier) named as Quadratic Boost Switched Capacitor Converter (QBSCC). It has numerous advantages like high voltage gain with single active switch and having provision to vary the level of output voltage by using switched capacitor circuit with self-balancing form. QBSCC also having the properties of non-minimum phase, so non-linear controller is adopted for improving the performance of the system. PID controller technique is broadly adopted for converter because it is simple, very effective and user friendly. It has solely three tuning parameters and it is lack of robustness.

Due to the non-linearity constraint of input and output variables several nonlinear control methods are developed. Recently nonlinear system design issues and analysis of uncertainties nonlinear problems are addressed by sliding mode approach where uncertainties are grouped in to unknown but bounded functions. It gives better performance in internal parameter variation, external disturbance and provides good results in fast transient response. To increase the stability of system and controller performance PID controller is replaced by fractional order PID controller. Fractional PID controller has the advantage of additional tuning parameter (i.e., fractional integral and derivative parameter) [21, 22]. Genetic algorithm optimization method is used to tune the parameters of non- integer order and integer order controller. The performance results are analyzed and compared with integer order PID controller for Quadratic Boost Switched Capacitor Converter using the simulation platform of MATLAB/SIMULINK.

The rest of the paper is organized as follows. In Section 2 discussed about the operating principle, modes of operation, full order and reduce order model for QBSCC. Fractional order controller implementation for QBSCC is described in the Section 3. Performance comparison of QBSCC with integer order and non-integer order controller presented in Section 4. Finally, concluding remarks are drawn in Section 5.

\section{Quadratic Boost Switched Capacitor Converter 2.1 Operating principle}

The non-isolated quadratic boost converter switched capacitor converter operates is continuous conduction mode and produce output voltage in form of self-balancing. In QBSCC output voltage can be increased by adding the pair of switched capacitor (see Fig. 2). The proposed QBSCC has four different modes of operation with the time interval of $t_{0}, t_{1}, t_{2}$ and $t_{3}$ respectively.

Mode I: $\left(t_{0}-t_{1}\right)$ : During this ON state of switch SW, the diode $D_{1}$ is in reverse biased condition and diode $D_{2}$ is in forward biased condition. In this period the inductor $L_{1}$ stores energy from input voltage $E$ and the inductor $L_{2}$ stores the energy from voltage in capacitor $C_{1}$ is shown in Fig. 3 (a). Hence the capacitor energy $C_{1}$ discharges slowly through the inductor $L_{2}$.

Mode II: $\left(t_{1}-t_{2}\right)$ : During this period, the switch SW remains in turn $\mathrm{ON}$ state, the diode $D_{1}, D_{2}$ position remain same as reverse biased and forward biased respectively. However, diode $D_{4}$ starts conducting, due to $C_{4}$ 's voltage is smaller than $C_{2}$ 's voltage then $C_{2}$ clamps $C_{4}$ 's voltage through $D_{4}$ depicts in Fig. 3 (b) and Fig. 4.

Mode III: $\left(t_{2}-t_{3}\right)$ : Fig. 3 (c) shows the switch SW in OFF state, here the diode $D_{1}$ and $D_{3}$ are forward biased and diode $D_{2}, D_{4}, D_{5}$ are operated in reverse biased condition. Hence the energy stored in both the inductors $L_{1}$ and $L_{2}$ got discharged. Meanwhile, the voltage across capacitor $C_{1}$ start charging through $D_{1}$ and the capacitor $C_{2}$ is charged through inductor $L_{2}$ by the conduction of the diode $D_{5}$. Similarly, $C_{2}$ and $C_{3}$ are also charged by conduction of diode $D_{3}$.

Mode IV: $\left(t_{3}-t_{4}\right)$ : The position of switch remains same as previous mode (OFF state). When $D_{3}$ closes, capacitor $C_{4}$ and the input voltage E plus the inductor's voltage clamp the voltage across $C_{2}$ and $C_{3}$ through $D_{5}$ (see Fig. 3 (d)). The continuous conduction mode state of operation is presented in Fig. 4. Based on the four modes of QBSCC operation, dynamic behavior of the system is derived with two LTI models (i.e., ON state and OFF state).

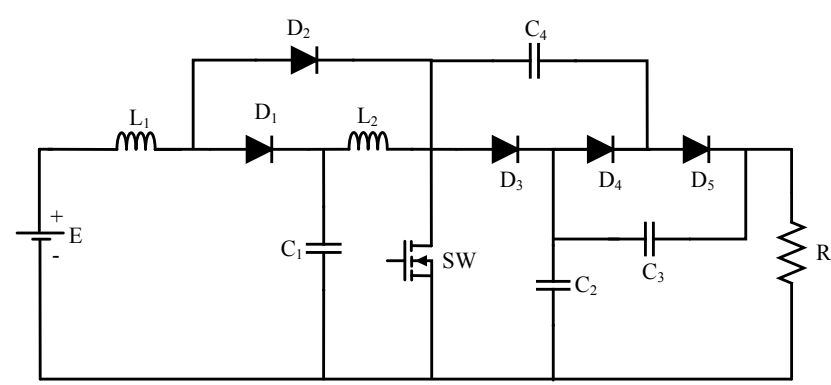

Fig. 2 Quadratic Boost Switched Capacitor Converter 


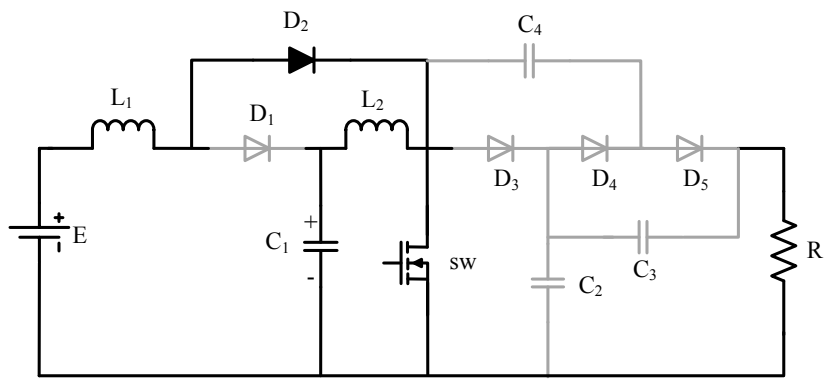

(a)

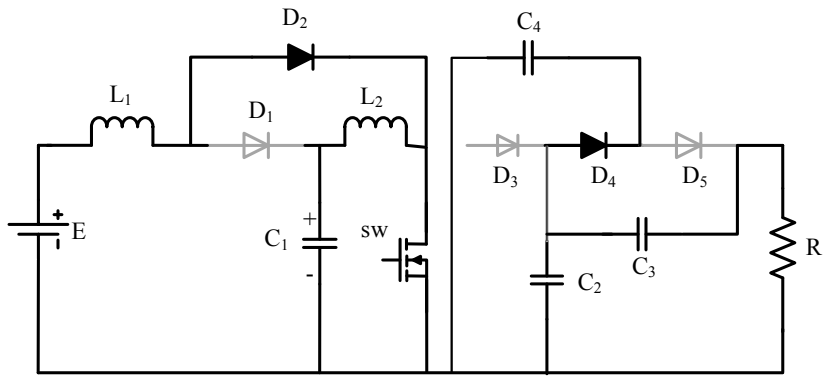

(b)

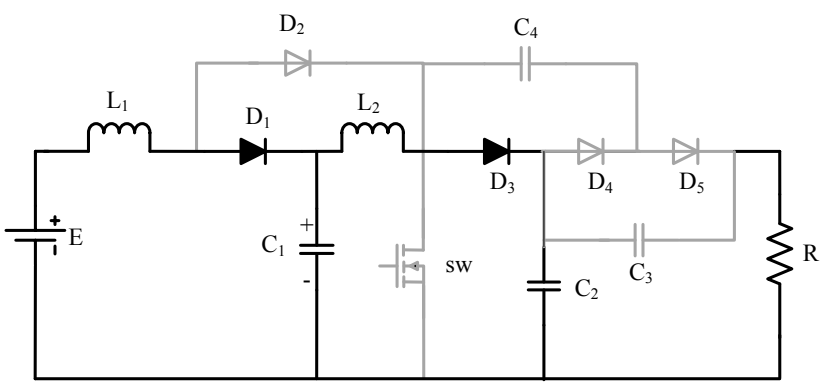

(c)

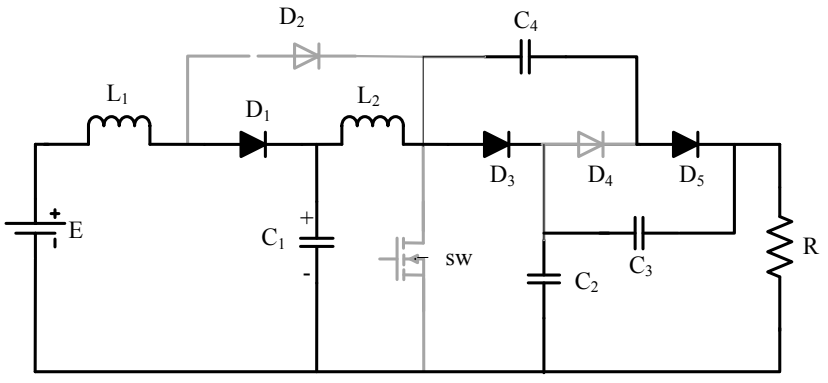

(d)

Fig. 3 Modes of operation of the QBSCC

\subsection{Modelling of Quadratic Boost Switched Capacitor}

\section{Converter}

To obtain the transfer function of the proposed converter, the full order state space model is derived. Since the proposed converter has single switch, two different model is derived. During switch ON state one model is obtained and during switch OFF state another model is obtained. The input voltage for the converter is $E$. The state variables in the circuit are voltage across capacitor $C_{1}$ denoted as $V_{C 1}$, current through the inductors $L_{1}$ and $L_{2}$ denoted as $i_{L 1}$, and $i_{L 2}$, voltage across capacitor $C_{1}, C_{2}, C_{3}, C_{4}$ denoted as $V_{C 1}, V_{1}, V_{2}$ and $V_{3}$ respectively.

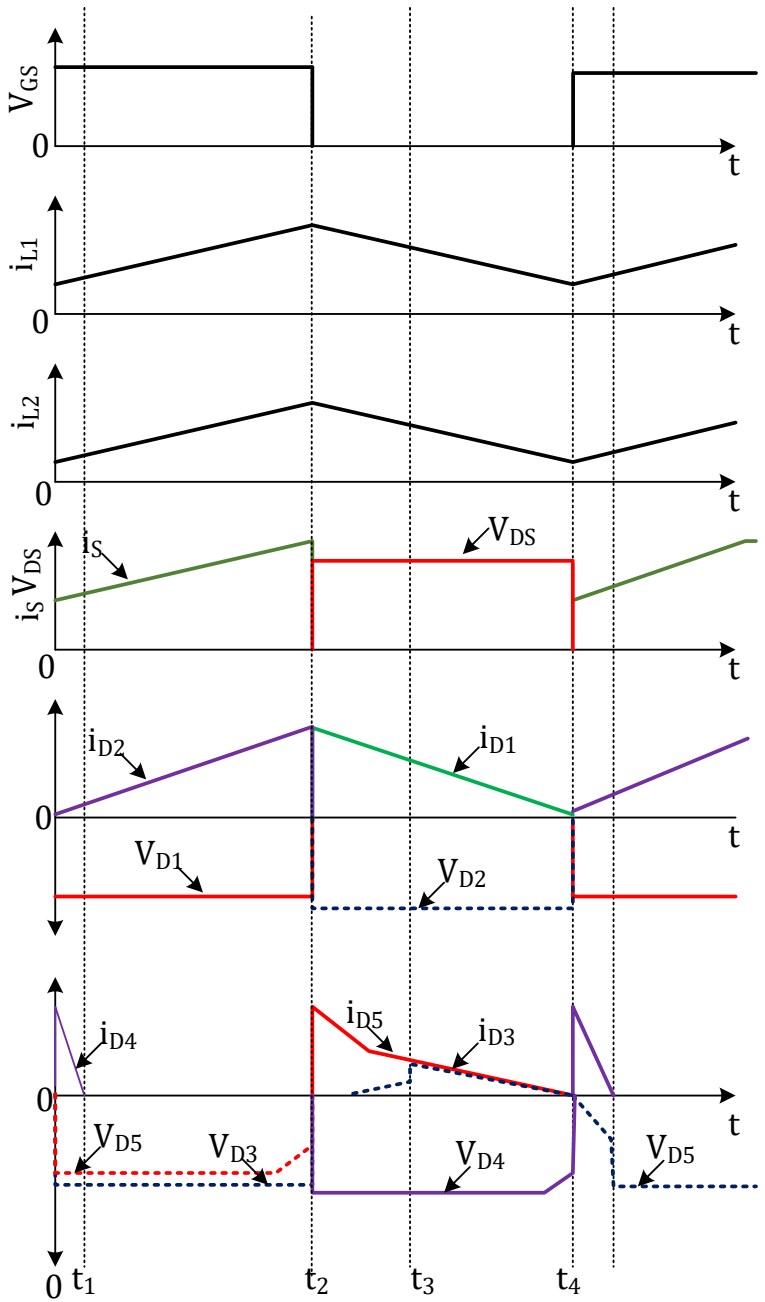

Fig. 4 Key waveform of CCM of QBSCC

The parameters are $R, L_{1}, L_{2}, C_{1}, C_{2}, C_{3}$, and $C_{4}$. Where $R$ represents the load and the load voltage is denoted as $V_{0}$. The state space model can be derived by writing the voltage loop equations. The $\mathrm{ON}$ state dynamic equations can be written using the Fig. 3 (b) and are given in Eq. (1). The OFF state dynamic equations can be derived using the model given in Fig. 3 (d) and are given in Eq. (2):

$$
\left.\begin{array}{rl}
\frac{d i_{L 1}}{d t} & =\frac{E}{L_{1}} \\
\frac{d i_{L 2}}{d t} & =\frac{V_{C 1}}{L_{2}} \\
\frac{d V_{C 1}}{d t} & =-\frac{i_{L 2}}{C_{1}} \\
\frac{d V_{1}}{d t} & =-\frac{V_{1}}{\left(C_{2}+C_{4}\right) R}-\frac{V_{2}}{\left(C_{2}+C_{4}\right) R} \\
\frac{d V_{2}}{d t} & =-\frac{V_{1}}{C_{3} R}-\frac{V_{2}}{C_{3} R} \\
\frac{d V_{3}}{d t} & =-\frac{V_{1}}{\left(C_{2}+C_{4}\right) R}-\frac{V_{2}}{\left(C_{2}+C_{4}\right) R}
\end{array}\right\},
$$




$$
\left.\begin{array}{l}
\frac{d i_{L 1}}{d t}=\frac{E}{L_{1}}-\frac{V_{C 1}}{L_{1}} \\
\frac{d i_{L 2}}{d t}=\frac{V_{C 1}}{L_{2}}-\frac{V_{C 2}}{L_{2}} \\
\frac{d V_{C 1}}{d t}=\frac{i_{L 1}}{C_{1}}-\frac{i_{L 2}}{C_{1}} \\
\frac{d V_{1}}{d t}=\frac{i_{L 2}}{C_{2}}-\frac{V_{1}}{C_{2} R}-\frac{V_{2}}{C_{3} R} \\
\frac{d V_{2}}{d t}=\frac{V_{1}}{\left(C_{2}+C_{3}\right) R}-\frac{V_{2}}{\left(C_{2}+C_{3}\right) R} \\
\frac{d V_{3}}{d t}=\frac{V_{1}}{\left(C_{3}+C_{4}\right) R}-\frac{V_{2}}{\left(C_{3}+C_{4}\right) R}
\end{array}\right\}
$$

\subsection{Reduced order model of Quadratic Boost Switched Capacitor Converter}

The voltage balancing feature of the Quadratic Boost Switched Capacitor Converter is obtaining a reduced order model. The derived reduced order model exhibits an approximate dynamics for the two levels QBSCC. This feature provides several advantages for the control design and implementations. In order to increase the gain of the converter, a diode-capacitor pair is added at the output. The reduced order model is convenient for simplification and this approach will focus only on output voltage across the load rather than to find voltage across every capacitor at the output. The reason to go for reduced order model because of its simplicity and robustness.

The dynamic behavior of the reduced order model is approximately equal to the full order model. The balancing form of voltage is present in capacitor which is connected across the load. Hence the value of capacitor and the value of voltage remain same. When increasing the number of voltage level in output, then the capacitor can be treated as series and parallel combination. In Fig. 5 (a), describes the reduced order ON state. Here capacitors $C_{2}$ and $C_{4}$ are in parallel, then the equivalent capacitor is taken as $C_{e q 1}$. Similarly, the Fig. 5 (b) explains the reduced order model of the circuit in switch OFF mode. Here the $C_{3}$ and $C_{4}$ are in series, $C_{2}$ is taken as $C_{\text {eq2 }}$. Here it is assumed that $C \approx C_{2} \approx C_{3} \approx C_{4}$ and $V_{1} \approx V_{2} \approx V_{3} \approx \ldots \approx V_{N} \approx \frac{V}{N} . V$ is the output voltage. The state equations are obtained using Kirchoff voltage law and Kirchoff current law. The dynamic nonlinear state equations of reduced order switch ON state and switch OFF state are given in Eq. (3) and Eq. (4):

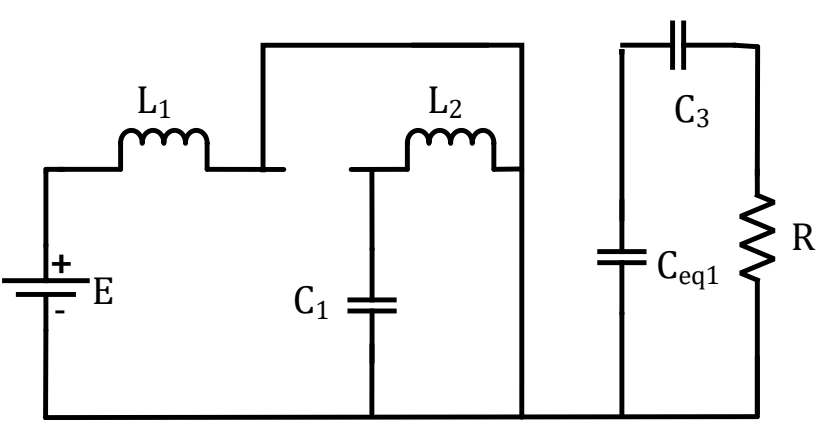

(a)

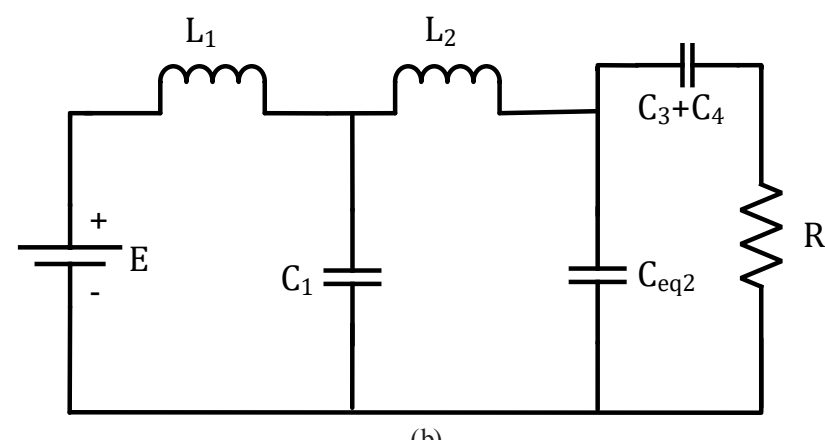

(b)

Fig. 5 Reduced order model of QBSCC

$$
\left.\begin{array}{c}
\frac{d i_{L 1}}{d t}=\frac{E}{L_{1}} \\
\frac{d i_{L 2}}{d t}=\frac{V_{C 1}}{L_{2}} \\
\frac{d V_{C 1}}{d t}=-\frac{i_{L 2}}{C_{1}} \\
\frac{d V}{d t}=-\frac{N V}{R C_{e q 1}}
\end{array}\right\}
$$

$\frac{d i_{L 1}}{d t}=\frac{E}{L_{1}}-\frac{V_{C 1}}{L_{1}}$

$\frac{d i_{L 2}}{d t}=\frac{V_{C 1}}{L_{2}}-\frac{V}{L_{2}}$

$\frac{d V_{C 1}}{d t}=\frac{i_{L 1}}{C_{1}}-\frac{i_{L 2}}{C_{1}}$

$\frac{d V}{d t}=\frac{i_{L 2}}{C_{e q 2}}-\frac{N V}{R C_{e q 2}}$

In the transient state analysis, the large signal model is evaluated for ON and OFF states of the circuit respectively and we get the values of $A_{1}, B_{1}, C_{1}, D_{1}$ from the ON state and $A_{2}, B_{2}, C_{2}, D_{2}$ from the OFF state. Using the above equation (Eq. (3) and Eq. (4)) averaged large signal model is formed from the Eq. (5), where $d$ denoted the duty ratio: 


$$
\left.\begin{array}{l}
A=A_{1} d+A_{2}(1-d) \\
B=B_{1} d+B_{2}(1-d) \\
C=C_{1} d+C_{2}(1-d) \\
D=d_{1} d+D_{2}(1-d)
\end{array}\right\} .
$$

The average state space model of the reduced order Quadratic Boost Switched Capacitor Converter is shown in Eq. (6). Small signal model is arrived by replacing derivative $\dot{x}=0$, duty cycle $d$ is replaced as $\hat{d} . A \hat{x}+B \hat{u}$ is termed as small signal model, here $\hat{x} \times \hat{d}$ assumed to be neglected and $\dot{x}=A x+B u=0$.

$$
\begin{aligned}
& \dot{\hat{x}}=A \hat{x}+B \hat{u}+\left[\left(A_{1}-A_{2}\right) x+\left(B_{1}-B_{2}\right) u\right] \hat{d} \\
& \hat{y}=C \hat{x}+D \hat{u}+\left[\left(C_{1}-C_{2}\right) x+\left(D_{1}-D_{2}\right) u\right] \hat{d}
\end{aligned}
$$

Similarly, the output state equation is given in Eq. (7). $x(t)=\left[\begin{array}{llllll}i_{L 1} & i_{L 2} & V_{C 1} & V_{C 2} & V_{C 3} & V_{C 4}\end{array}\right]^{T} \in R^{4}$ are the average values of the state vector, $A$ is the matrix in $R^{4 \times 4}$ and $B$ is a vector of $R^{4}$. The parasitic capacitance is comparatively small and is neglected for simplicity purpose. The representation of the matrix is nonlinear depends on the control signal $\hat{d}$. General small signal model state equation and output equations are written in the Eq. (8) and Eq. (9):

$\dot{\hat{x}}=A \hat{x}+B \hat{u}$,

$\hat{y}=C \hat{x}+D \hat{u}$.

The voltage ripple in the all capacitor considered as zero and power loss in the switch also not considered. The small signal model state space equation for the Quadratic Boost Switched Capacitor Converter is given in Eq. (10):

$$
\begin{aligned}
& {\left[\begin{array}{c}
\dot{i_{L 1}} \\
\dot{i_{L 2}} \\
\dot{\widehat{V_{C 1}}} \\
\dot{\hat{V}}
\end{array}\right]=\left[\begin{array}{cccc}
0 & 0 & -\frac{(1-D)}{L_{1}} & 0 \\
0 & 0 & \frac{1}{L_{2}} & \frac{(1-D)}{L_{2}} \\
\frac{(1-D)}{C_{1}} & -\frac{1}{C_{1}} & \frac{1}{L_{2}} & 0 \\
0 & \frac{(1-D)}{C} & 0 & -\frac{N}{2 C R}-\frac{N(1-D)}{C R}
\end{array}\right]} \\
& {\left[\begin{array}{c}
\widehat{i_{L 1}} \\
\widehat{i_{L 2}} \\
\widehat{V_{C 1}} \\
\hat{V}
\end{array}\right]+\left[\begin{array}{ll}
\frac{E}{(1-D) L_{1}} & \frac{1}{L_{1}} \\
\frac{E}{(1-D)^{2} L_{2}} & 0 \\
-\frac{\left(\frac{3}{2}-D\right) N E}{(1-D)^{4} R C_{1}} & 0 \\
-\frac{\left(\frac{3}{2}-D\right) N E}{(1-D)^{3} R C}+\frac{N E}{(1-D)^{2} C_{1}} & 0
\end{array}\right] .}
\end{aligned}
$$

Based on the Eq. (11), the transfer function of output voltage to duty ratio is derived and it expression is given in Eq. (12), where $\hat{e}=0$.

$\frac{\hat{V}}{\hat{d}}=C[S I-A]^{-1} B$

$\frac{\hat{V}}{\hat{d}}=\frac{2.5 \times 10^{6} s^{3}+4 \times 10^{10} s^{2}+8.5 \times 10^{13} s+1.3 \times 10^{20}}{s^{4}+4410 s^{3}+1.3 \times 10^{7} s^{2}+1.1 \times 10^{13} s+8.2 \times 10^{17}}$

From the transfer function (output voltage to duty ratio). Zeros are located at $(-4267,13348 \pm$ i31447), Poles are located at $(-31901 \pm \mathrm{i} 29981,-28138)$. The operating frequency of the MOSFET is $40 \mathrm{kHz}$. The bode plot for the transfer function is given in Fig. 6.

Fuel cell output is unregulated and it is dynamic behavior, this output of the fuel cell is given to the Quadratic Boost Switched Capacitor Converter as an input. Due to dynamic behavior in the input source the converter delivers an output with large variation. Also large variation in load affects the performance of the converter, so the controller is necessary with high performance for fast transient response and good regulation when an unregulated source is used and load variation is occur. For achieving good dynamic and steady state response PID controller is extensively used. The proportional factor gives an overall control action which is proportional to the error signal through constant gain factor. Steady state error reduced through low-frequency compensation by an integrator. Similarly, transient response improved through high frequency compensation by a differentiator.

The main advantage of Fractional-order controller is that it provides more adjustable time and frequency responses of the control system allowing fulfillment of better as well as robust performance. So a fractional-order controller will always provide better response than integer-order controller if it is properly tuned whatever may

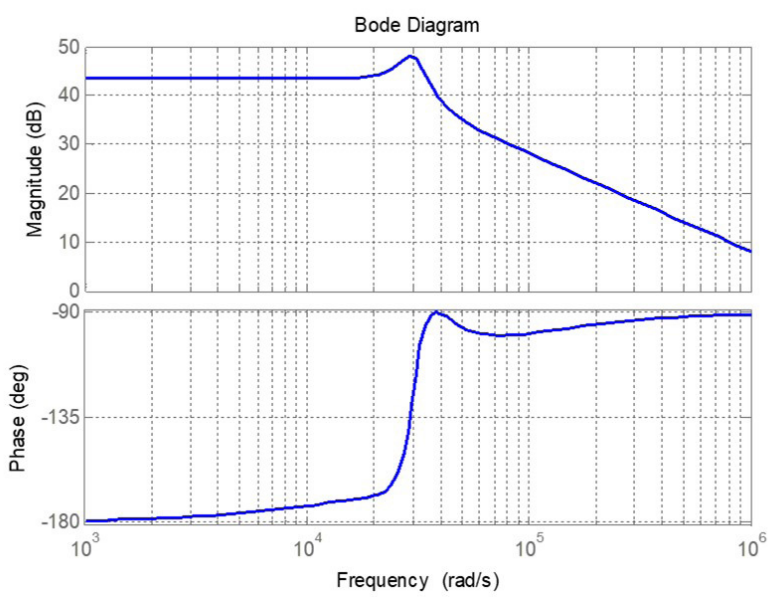

Fig. 6 Bode plot of QBSCC 
be the type of plant (integer or fractional). It provides more degrees of freedom than its integer order counterpart.

The proposed QBSCC converter is behaving as non-minimum phase system. In order to reduce the complication, the optimization technique is used for obtaining the parameters present in controller. In this proposed work IOPID controller is designed and the gain of the controller is optimized by the genetic algorithm tuning method.

\section{Fractional order PID controller}

There are analytical, numerical and rule-based techniques and are presented for tuning the parameters of FOPID controller and those methods are explained in [22]. The parameters derived from nonlinear equations gives better results by satisfying phase margin and gain margin for the given specification [23]. If the system is first order and the equation is simple, then analytical method is appropriate. For the higher order systems like fourth order or fifth order systems, the design of the parameter of $P I^{\lambda} D^{\mu}$ for the given converter system, is discussed in the paper [24-27]. The rule based technique is also difficult, because of the unstable behavior of the controller plant [28-30]. Compared to the analytical and rule based system, numerical technique is more convenient for obtaining the controller parameters for higher order system, which is optimization based method. In [31], load disturbance constraint is addressed and also deals the integral gain optimization algorithm for tuning FOPI controller. Tuning and auto tuning algorithm are proposed in [32], MATLAB optimization toolbox is adopted to solve this problem:

$$
a D_{t}^{r}= \begin{cases}\frac{d^{r}}{d t^{r}} & \mathrm{R}(r)>0, \\ 1 & \mathrm{R}(r)=0, . \\ \int_{\alpha}^{t}(d \tau)^{-r} & \mathrm{R}(r)<0\end{cases}
$$

The basic definition of fractional calculus is discussed in $[33,34]$. The generalized operator function is given in Eq. (13).

$" r$ " denotes as complex number. Rienmann-Liouville (RL) definition, Grunewald-Letnikov (GL) definition and Caputo fractional derivatives are coincide at zero initial conditions. All these three methods are suitable to eliminate the difference arising due to different initial conditions. The corresponding relations are given in the Eqs. (14)-(16): $a D_{t}^{r} f(t)=\frac{1}{\Gamma(n-\alpha)}\left(\frac{d}{d t}\right)^{n} \int_{\alpha}^{t} \frac{f(\tau)}{(t-\tau)^{\alpha-n+1}} d \tau$,
${ }_{a}^{C} D_{t}^{\alpha} f(t)=\lim _{h \rightarrow 0} h^{-\alpha} \sum_{j=0}^{\left[\frac{t-a}{h}\right]}(-1)^{j}\left(\begin{array}{c}\alpha \\ j\end{array}\right) f(t-j h)$,

${ }_{a}^{C} D_{t}^{\alpha} f(t)=\frac{1}{\Gamma(n-\alpha)} \int_{\alpha}^{t} \frac{f^{n}(\tau)}{(t-\tau)^{\alpha+1-n}} d \tau$.

$(n-1) \leq \alpha<n$, where $\alpha$ is a real number, and $n$ is an integer. The general form of $G(z)$ of discrete transfer function of the controlled system is represented by the Eq. (17):

$$
G(z)=\frac{b_{m}\left(w\left(z^{-1}\right)\right)^{\beta_{m}}+\ldots+b_{0}\left(w\left(z^{-1}\right)\right)^{\beta_{0}}}{a_{n}\left(w\left(z^{-1}\right)\right)^{\alpha_{n}}+\ldots+b_{0}\left(w\left(z^{-1}\right)\right)^{\alpha_{0}}} .
$$

The discrete value of Laplace operator denoted as $w\left(z^{-1}\right)$ in the form of complex variable $z$. The generalized transfer function of the fractional order PID $\left(P I^{\lambda} D^{\mu}\right)$ controller is presented in the Eq. (18):

$C(s)=\frac{V_{0}(s)}{E(s)}=K_{p}+T_{i} s^{\lambda}+T_{d} s^{\mu}$.

The discrete value of Laplace operator denoted as $w\left(z^{-1}\right)$ in the form of complex variable $z$. The generalized transfer function of the fractional order PID $\left(P I^{\lambda} D^{\mu}\right)$ controller is presented in the Eq. (14). In Eq. (14) positive real numbers are denoted by $\lambda$ and $\mu . K_{p}, T_{i}, T_{d}$ are proportional gain, integral time constant and derivative time constant respectively. The integer order PID controller can be obtained from the non-integer controller making the assumption of $\lambda=-1$ and $\mu=1$. If the value of $\lambda$ is kept as zero then the controller termed as PD controller. Correspondingly $\mu=0$ will result in PI controller. The time domain function is stated and is given in Eq. (19):

$u(t)=K_{p} e(t)+T_{i} D_{t}^{\lambda} e(t)+T_{d} D_{t}^{\mu} e(t)$.

$P I^{\lambda} D^{\mu}$ controller accommodates more tuning parameter to enhance the control system performance. $P I^{\lambda} D^{\mu}$ is an infinite dimensional linear filter because of fractional order in differentiator and/or in integrator. Since PID control is omnipresent in portable hybrid electric vehicle and industrial process control, FO PID control will also become omnipresent once tuning and implementation techniques are well developed. Some typical fractional order controllers which are introduced in literature are namely, TID (Tilted Integral Derivative) controller, CRONE controller and fractional lead-lag compensator.

\subsection{Objective function of genetic algorithm}

Genetic algorithm optimization method is popular and operation is carried by natural way. It randomly generates the solution by population; it is believed that good solutions are to be evolved by applying the genetic operations, 
namely, cross over and mutation on some selected parents [35]. It is used to search the best solution that problem arises from maximizing the fitness function. The Integral Absolute Error (IAE) function is used as an objective function and is given in Eq. (20). The purpose of error function is to reduce the peak overshoot, fastening the settling time and improving the system performance:

$$
\operatorname{IAE}=\int|e(t)| d t .
$$

This fitness function is then optimized by GA such that the voltage and current errors get reduced with the optimized $K_{p}, K_{i}$ and $K_{d}$. The performance measure used in this present case is the minimization of Integral of Average Error (IAE). The fitness function is given as the inverse of IAE. The optimum values obtained for the PID and FOPID controllers using the genetic algorithms were given in Table 1.

\section{Performance analysis}

The Quadratic Boost Switched Capacitor Converter with PID controller and FOPID controller were implemented using MATLAB/SIMULINK. The component designs are carried for the proposed system for the nominal power of $250 \mathrm{~W}, 400 \mathrm{~V}$. It provides better voltage gain with reduced duty ratio $(D=0.5)$. The voltage gain expressed as a ratio of output voltage to input voltage given in Eq. (21):

$\frac{V_{o}}{E}=\frac{N}{(1-D)^{2}}$.

Here $N$ represents number of diode capacitor pair. It has the provision for increasing the voltage gain either by increasing duty ratio or by adding diode capacitor pairs across load. The load resistor varies from $200 \Omega$ to $600 \Omega$. The switch operates at the switching frequency of $40 \mathrm{kHz}$. The transfer function of output voltage to duty ratio $\frac{\hat{v}_{o}}{\hat{d}}$ exhibits the fourth order relation. The components values are designed based on the relation given in [36]. The parameters are decided from the design formula given in Eq. (22) to Eq. (25):

$$
\begin{aligned}
& L_{1}=\frac{E D}{\delta i_{L 1} f_{s w}}, \\
& L_{2}=\frac{E D}{\delta i_{L 2}(1-D) f_{s w}},
\end{aligned}
$$

Table 1 Parameters of PID and fractional order PID controller

\begin{tabular}{lccccc}
\hline parameter & $K_{p}$ & $K_{i}$ & $K_{d}$ & $\lambda$ & $\mu$ \\
\hline FOPID & 4.724 & 2.512 & 1.726 & 0.1229 & 0.6122 \\
PID & 1.009 & 1.682 & 2.94 & 1 & 1 \\
\hline
\end{tabular}

$C_{1}=\frac{I_{0} D}{(1-D) \Delta V_{C 1} f_{s w}}$,

$C_{2}=C_{3}=C_{4}=\frac{I_{0} D}{\Delta V_{C 2} f_{s w}}$

The parameters of the FOPID controllers were obtained using genetic algorithms optimization toolbox. The converter with fractional order PID controller design is given in Fig. 7, and the specification of the converter is given in Table 2.

Line regulation and load regulation analysis are carried and the performance in steady state and dynamic conditions were tested. Fig. 8 shows the responses of the system with PID and FOPID controllers. It is found that the initial peak overshoot is more for FOPID controller. But the performance of the FOPID controller is better during load changes. Fig. 8 exhibits the load variation from $600 \Omega$ to $400 \Omega$, i.e., approximately $60 \%$ of load variation. The load change is applied at $0.1 \mathrm{sec}$; undershoot of voltage present in PID controller for $0.03 \mathrm{sec}$ with magnitude of $27 \mathrm{~V}$. But this undershoot problem not present in FOPID controller. Also it has reduced voltage magnitude approximately $6 \mathrm{~V}$.

The simulation results of Fig. 9 shows the line voltage variation results, when the line voltage is varied from $40 \mathrm{~V}$ to $50 \mathrm{~V}$ at $0.1 \mathrm{sec}$. It is found that the input voltage disturbance does not affect the system performance when a FOPID controller is used. In contrast a PID controller response has produce overshoot, when the input voltage changed.

The system with PID controller the peak overshoot value is around $460 \mathrm{~V}$ with short settling time $250 \mu \mathrm{sec}$. The transient response of the proposed converter with FOPID controller operating at nominal load of $400 \Omega$ does not show much peak overshoot. The performance comparison of the dynamic behavior of system under perturbations with PID and FOPID controller is given in Table 3. From the Table 3 it is found that the peak overshoot and settling time is much better for the system with FOPID controller.

\section{Conclusion}

In this work a fractional order PID controller was designed for the Quadratic Boost Switched Capacitor Converter using genetic algorithm optimization method. The Quadratic Boost Switched Capacitor Converter with FOPID controller was implemented using MATLAB/Simulink and its performance was analyzed. An integer order PID controller also designed and implemented for Quadratic Boost Switched Capacitor Converter and the performance of the converter with both the controller were compared. 


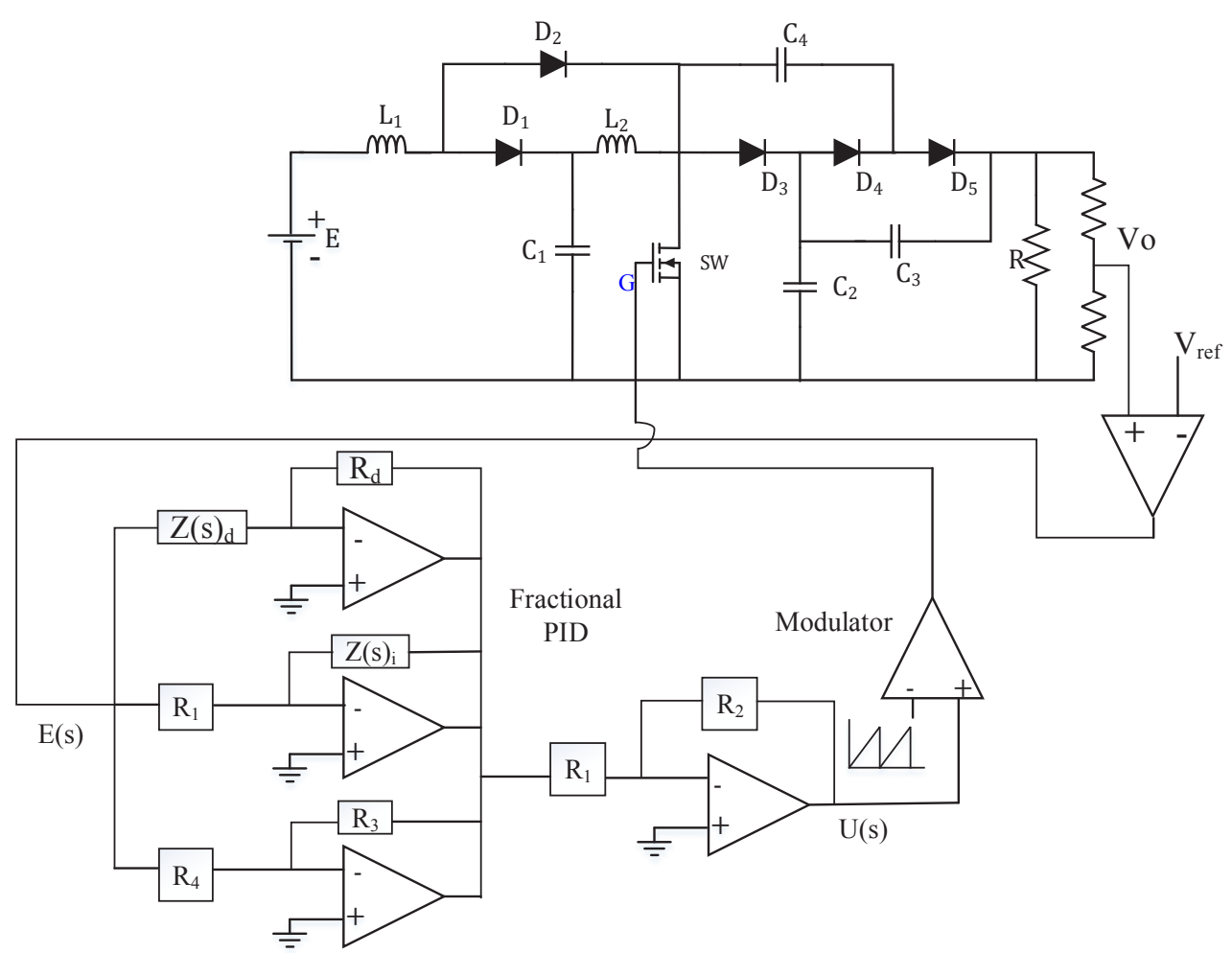

Fig. 7 Fractional order PID controller for Quadratic Boost Switched Capacitor Converter

Table 2 Parameters of the QBSCC

\begin{tabular}{lc}
\hline Input voltage $(E)$ & $50 \mathrm{~V}$ \\
\hline Output voltage $\left(V_{0}\right)$ & $400 \mathrm{~V}$ \\
Duty cycle range $(D)$ & 0.5 to 0.9 \\
Capacitor 1 $\left(C_{1}\right)$ & $5 \mu \mathrm{F}$ \\
Inductor 1 $\left(L_{1}\right)$ & $156 \mu \mathrm{H}$ \\
Inductor 2 $\left(L_{2}\right)$ & $312 \mu \mathrm{H}$ \\
Load resistor $(R)$ & $200 \Omega$ \\
Capacitor $\left(C_{1}, C_{2}, C_{3}\right)$ & $10 \mu \mathrm{F}$ \\
Switching frequency $\left(f_{s w}\right)$ & $40 \mathrm{kHz}$ \\
\hline
\end{tabular}

In load variations, the output is well regulated in both the controller. The steady state and dynamic response is better for FOPID controller. Settling time on load variation and line variation, FOPID controller works much better than PID. But during initial transient response condition the FOPID, has pronounced peak overshoot. While in PID peak overshoot is minimum in transient condition, but the settling time in PID. From the results suggest that FOPID controller is better than PID controller during input voltage variation and load current variation conditions.

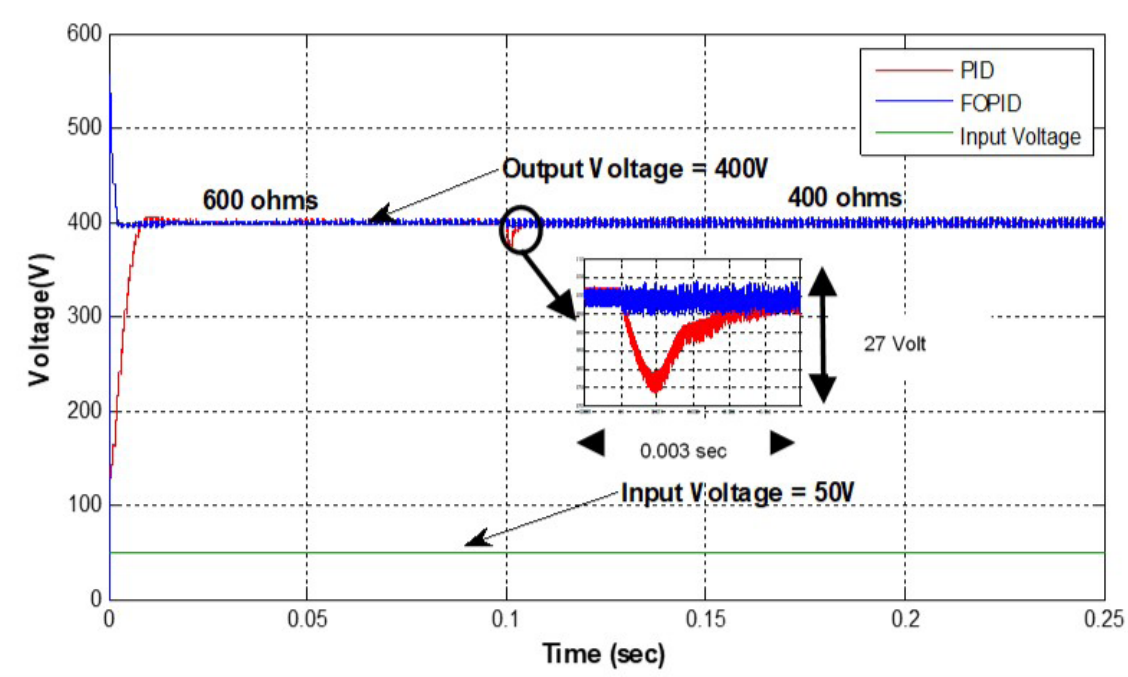

Fig. 8 Comparison of transient response under changes on load from $600 \Omega$ to $400 \Omega$ 


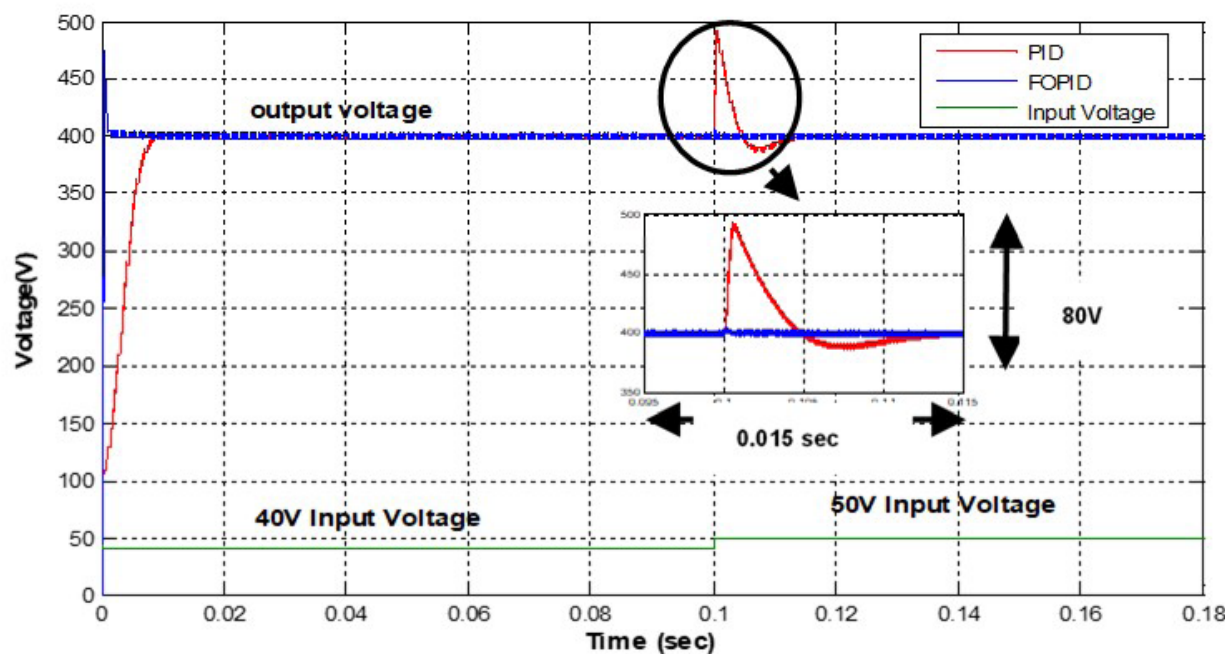

Fig. 9 Comparison of transient response under changes on input voltage from $40 \mathrm{~V}$ to $50 \mathrm{~V}$

Table 3 Performance comparison

\begin{tabular}{|c|c|c|c|c|c|}
\hline \multirow{2}{*}{ Parameter } & & \multicolumn{2}{|c|}{ Fractional order controller } & \multicolumn{2}{|c|}{ Integer order controller } \\
\hline & & Settling time (sec) & Over shoot (\%) & Settling time (sec) & Over shoot (\%) \\
\hline \multirow{2}{*}{ Dynamic response } & Load variation & 0.001 & 1.25 & 0.003 & 6.7 \\
\hline & Line variation & 0.001 & 1.05 & 0.016 & 20 \\
\hline
\end{tabular}

\section{References}

[1] Shimizu, T., Wada, K., Nakamura, N. "Flyback-Type Single-Phase Utility Interactive Inverter With Power Pulsation Decoupling on the DC Input for an AC Photovoltaic Module System", IEEE Transactions on Power Electronics, 21(5), pp. 1264-1272, 2006. https://doi.org/10.1109/TPEL.2006.880247

[2] Pogaku, N., Prodanovic, M., Green, T. C. "Modeling, Analysis and Testing of Autonomous Operation of an Inverter-Based Microgrid", IEEE Transactions on Power Electronics, 22(2), pp. 613-625, 2007. https://doi.org/10.1109/TPEL.2006.890003

[3] Li, W., He, X. "Review of Nonisolated High-Step-Up DC/DC Converters in Photovoltaic Grid-Connected Applications", IEEE Transactions on Industrial Electronics, 58(4), pp. 1239-1250, 2011. https://doi.org/10.1109/TIE.2010.2049715

[4] Tofoli, F. L., de Castro Pereira, D., Josias de Paula, W., de Sousa Oliveira Júnior, D. "Survey on non-isolated high-voltage step-up dc-dc topologies based on the boost converter", IET Power Electronics, 8(10), pp. 2044-2057, 2015. https://doi.org/10.1049/iet-pel.2014.0605

[5] Papanikolaou, N. P., Tatakis, E. C. "Active voltage clamp in flyback converters operating in CCM mode under wide load variation", IEEE Transactions on Industrial Electronics, 51(3), pp. 632-640, 2004. https://doi.org/10.1109/TIE.2004.825342

[6] Chen, S. M., Liang, T. J., Yang, L. S., Chen, J. F. "A Safety Enhanced, High Step-Up DC-DC Converter for AC Photovoltaic Module Application", IEEE Transactions on Power Electronics, 27(4), pp. 1809-1817, 2012.

https://doi.org/10.1109/TPEL.2011.2170097
[7] Khaligh, A., Li, Z. "Battery, Ultracapacitor, Fuel Cell and Hybrid Energy Storage Systems for Electric, Hybrid Electric, Fuel Cell, and Plug-In Hybrid Electric Vehicles: State of the Art", IEEE Transactions on Vehicular Technology, 59(6), pp. 2806-2814, 2010. https://doi.org/10.1109/TVT.2010.2047877

[8] Bauman, J., Kazerani, M. "A Comparative Study of Fuel-Cell-Battery, Fuel-Cell-Ultracapacitor, and Fuel-Cell-Battery-Ultracapacitor Vehicles", IEEE Transactions on Vehicular Technology, 57(2), pp. 760-769, 2008.

https://doi.org/10.1109/TVT.2007.906379

[9] Wang, C. S., Stielau, O. H., Covic, G. A. "Design considerations for a contactless electric vehicle battery charger", IEEE Transactions on Industrial Electronics, 52(5), pp. 1308-1314, 2005. https://doi.org/10.1109/TIE.2005.855672

[10] Moeini-Aghtaie, M., Abbaspour, A., Fotuhi-Firuzabad, M. "Online Multicriteria Framework for Charging Management of PHEVs", IEEE Transactions on Vehicular Technology, 63(7), pp. 3028-3037, 2014.

https://doi.org/10.1109/TVT.2014.2320963

[11] Zhang, T., Chen, W., Han, Z., Cao, Z. "Charging Scheduling of Electric Vehicles With Local Renewable Energy Under Uncertain Electric Vehicle Arrival and Grid Power Price", IEEE Transactions on Vehicle Technology, 63(6), pp. 2600-2612, 2014. https://doi.org/10.1109/TVT.2013.2295591 
[12] Kabalo, M., Paire, D., Blunier, B., Bouquain, D., Simoes, M. G., Miraoui, A. "Experimental Validation of High-Voltage-Ratio Low-Input-Current-Ripple Converters for Hybrid Fuel Cell Supercapacitor Systems", IEEE Transactions on Vehicular Technology, 61(8), pp. 3430-3440, 2012. https://doi.org/10.1109/TVT.2012.2208132

[13] Pires, V. F., Cordeiro, A., Foito, D., Silva, J. F. "High Step-Up DCDC Converter for Fuel Cell Vehicles Based on Merged Quadratic Boost-Ćuk", IEEE Transactions on Vehicular Technology, 68(8), pp. 7521-7530, 2019.

https://doi.org/10.1109/TVT.2019.2921851

[14] Wang, Y., Qiu, Y., Bian, Q., Guan, Y., Xu, D. "A Single Switch Quadratic boost High Step Up DC-DC Converter", IEEE Transactions on Industrial Electronics, 66(6), pp. 4387-4397, 2019. https://doi.org/10.1109/TIE.2018.2860550

[15] Alonge, F., Rabbeni, R., Pucci, M., Vitale, G. "Identification and Robust Control of a Quadratic DC/DC Boost Converter by Hammerstein Model", IEEE Transactions on Industry Applications, 51, (5), pp. 3975-3985, 2015. https://doi.org/10.1109/TIA.2015.2416154

[16] Carbajal-Gutierrez, E. E., Morales-Saldana, J. A., LeyvaRamos, J. "Modeling of a single-switch quadratic buck converter", IEEE Transactions on Aerospace and Electronic Systems, 41(4), pp. 1450-1456, 2005. https://doi.org/10.1109/TAES.2005.1561895

[17] Leyva-Ramos, J., Ortiz-Lopez, M. G., Diaz-Saldierna, L. H., Morales-Saldana, J. A. "Switching regulator using a quadratic boost converter for wide DC conversion ratios", IET Power Electronics, 2(5), pp. 605-613, 2009. https://doi.org/10.1049/iet-pel.2008.0169

[18] Morales-Saldaña, J. A., Loera-Palomo, R., Palacios-Hernández, E., González-Martínez, L. "Modelling and control of a DC-DC quadratic boost converter with $R^{2} P^{2 "}$, IET Power Electronics, 7(1), pp. 11-22, 2014. https://doi.org/10.1049/iet-pel.2012.0749

[19] Morales-Saldaña, J. A., Galarza-Quirino, R., Leyva-Ramos, J., Carbajal-Gutierrez, E. E., Ortiz-Lopez, M. G. "Multiloop controller design for a quadratic boost converter", IET Electric Power Applications, 1(3), pp. 362-367, 2007. https://doi.org/10.1049/iet-epa:20060426

[20] López-Santos, O., Martínez-Salamero, L., García, G., ValderramaBlavi, H., Mercuri, D. O. "Efficiency analysis of a sliding-mode controlled quadratic boost converter", IET Power Electronics, 6(2), pp. 364-373, 2013. https://doi.org/10.1049/iet-pel.2012.0417

[21] Podlubny, I. "Fractional-Order Systems and $P I^{\lambda} D^{\mu}$-Controllers", IEEE Transactions on Automatic Control, 44(1), pp. 208-214, 1999. https://doi.org/10.1109/9.739144

[22] Petras, I. "The fractional-order controllers: Methods for their synthesis and application", [math.OC], arXiv:math/0004064, Cornell University, Ithaca, NY, USA, 2000, [online] Available at: https:// arxiv.org/abs/math/0004064v1 [Accessed: 11 August 2018]

[23] Zhao, C., Xue, D., Chen, Y. Q. "A fractional order PID tuning algorithm for a class of fractional order plants", In: IEEE International Conference Mechatronics and Automation, Niagara Falls, Canada, 2005, pp. 216-221.

https://doi.org/10.1109/ICMA.2005.1626550
[24] Chen, Y. Q., Dou, H., Vinagre, B. M.. Monje, C. A. "A Robust Tuning Method for Fractional Prder PI Controllers", IFAC Proceedings Volumes, 39(11), pp. 22-27, 2006. https://doi.org/10.3182/20060719-3-PT-4902.00003

[25] Luo, Y., Li, H., Chen, Y. "Fractional order proportional and derivative controller synthesis for a class of fractional order systems: Tuning rule and hardware-in-the-loop experiment", In: Proceedings of the 48th IEEE Conference on Decision and Control (CDC) held jointly with 2009 28th Chinese Control Conference, Shanghai, China, 2009, pp. 5460-5465. https://doi.org/10.1109/CDC.2009.5400806

[26] Luo, Chen, Y. Q., Wang, C. Y., Pi, Y. G. "Tuning fractional order proportional integral controllers for fractional order systems", Journal of Process Control, 20(7), pp. 823-831, 2010. https://doi.org/10.1016/j.jprocont.2010.04.011

[27] Malek, H., Luo, Y., Chen, Y. Q. "Identification and tuning fractional order proportional integral controllers for time delayed systems with a fractional pole", Mechatronics, 23(7), pp. 746-754, 2013. https://doi.org/10.1016/j.mechatronics.2013.02.005

[28] Valério, D., Sá da Costa, J. "Tuning of fractional PID controllers with Ziegler-Nichols-type rules", Signal Processing, 86(10), pp. 2771-2784, 2006. https://doi.org/10.1016/j.sigpro.2006.02.020

[29] Valério, D., Sá da Costa, J. "Tuning Rules for Fractional PIDs", In: Sabatier, J., Agrawal, O. P., Machado, J. A. T. (eds.) Advances in Fractional Calculus, Springer, Dordrecht, Netherlands, 2007, pp. 463-476. https://doi.org/10.1007/978-1-4020-6042-7_32

[30] Bhambhani, V., Chen, Y. Q., Xue, D. "Optimal Fractional Order Proportional Integral Controller for Varying Time-Delay Systems", IFAC Proceedings Volumes, 41(2), pp. 4910-4915, 2008. https://doi.org/10.3182/20080706-5-KR-1001.00825

[31] Chen, Y. Q., Bhaskaran, T., Xue, D. "Practical Tuning Rule Development for Fractional Order Proportional and Integral Controllers", Journal of Computational and Nonlinear Dynamics, 3(2), Article Number: 021403, 2008. https://doi.org/10.1115/1.2833934

[32] Monje, C. A., Vinagre, B. M., Feliu, V., Chen, Y. Q. "Tuning and auto-tuning of fractional order controllers for industry applications", Control Engineering Practice, 16(7), pp. 798-812, 2008. https://doi.org/10.1016/j.conengprac.2007.08.006

[33] Podlubny, I. "Fractional Differential Equations", Academic Press, San Diego, CA, USA, 1999.

[34] Das, S. "Functional Fractional Calculus for System Identification and Controls", Springer-Verlag, Berlin, Heidelberg, Germany, 2008. https://doi.org/10.1007/978-3-540-72703-3

[35] Man, K. F., Tang, K. S., Kwong, S. "Genetic Algorithms: Concepts and Applications", IEEE Transactions on Industrial Electronics, 43(5), pp. 519-534, 1996 https://doi.org/10.1109/41.538609

[36] Sivaraj, D., Arounassalame, M. "High gain quadratic boost switched capacitor converter for photovoltaic applications", In: 2017 IEEE International Conference on Power, Control, Signals and Instrumentation Engineering (ICPCSI), Chennai, India, 2017, pp. 1234-1239. https://doi.org/10.1109/ICPCSI.2017.8391907 